\title{
Respiratory acidosis during bronchoscopy- guided percutaneous dilatational tracheostomy: impact of ventilator settings and endotracheal tube size
}

Christian Karagiannidis $^{1 *+} \mathbb{D}$, Michaela L. Merten ${ }^{1 \dagger}$, Leo Heunks ${ }^{2}$, Stephan E. Strassmann ${ }^{1}$, Simone Schäfer ${ }^{1}$, Friederike Magnet ${ }^{1}$ and Wolfram Windisch ${ }^{1}$

\begin{abstract}
Background: The current study investigates the effect of bronchoscopy-guided percutaneous dilatational tracheostomy (PDT) on the evolution of respiratory acidosis depending on endotracheal tube (ET) sizes. In addition, the impact of increasing tidal volumes during the intervention was investigated.

Methods: Two groups of ICU-patients undergoing bronchoscopy-guided PDT with varying tidal volumes and tube sizes were consecutively investigated: $6 \mathrm{ml} / \mathrm{kg}(N=29$, mean age $57.4 \pm 14.5$ years $)$ and $12 \mathrm{ml} / \mathrm{kg}$ predicted body weight ( $N=34$, mean age $59.5 \pm 12.8$ years).

Results: The mean intervention time during all procedures was $10 \pm 3$ min. The combination of low tidal volumes and ETs of $7.5 \mathrm{~mm}$ internal diameter resulted in the most profound increase in $\mathrm{PaCO}_{2}(32.2 \pm 11.6 \mathrm{mmHg})$ and decrease in pH-value $(-0.18 \pm 0.05)$. In contrast, the combination of high tidal volumes and ETs of $8.5 \mathrm{~mm}$ internal diameter resulted in the least profound increase in $\mathrm{PaCO}_{2}(8.8 \pm 9.0 \mathrm{mmHg})$ and decrease of $\mathrm{pH}(-0.05 \pm 0.04)$. The intervention-related increase in $\mathrm{PaCO}_{2}$ was significantly lower when using higher tidal volumes for larger ET: internal diameter 7.5, 8.0 and 8.5: $P>0.05,=0.006$ and $=0.002$, respectively. Transcutaneous $\mathrm{PCO}_{2}$ monitoring revealed steadily worsening hypercapnia during the intervention with a high correlation of 0.87 and a low bias of $0.7 \pm 9.4 \mathrm{mmHg}$ according to the Bland-Altman analysis when compared to $\mathrm{PaCO}_{2}$ measurements.

Conclusions: Profound respiratory acidosis following bronchoscopy-guided PDT evolves in a rapid and dynamic process. Increasing the tidal volume from 6 to $12 \mathrm{ml} / \mathrm{kg}$ PBW was capable of attenuating the evolution of respiratory acidosis, but this effect was only evident when using larger ETs.
\end{abstract}

Trial registration: DRKS00011004. Registered 20th September 2016.

Keywords: Dilatational tracheostomy, Endotracheal tube, Hypercapnia, Respiratory acidosis, Transcutaneous $\mathrm{PCO}_{2}$

\section{Background}

Today, percutaneous dilatational tracheostomy (PDT) has become one of the most commonly used interventions in ICU medicine [1-4]. Different techniques have been developed, but guidance by video bronchoscope

\footnotetext{
* Correspondence: Christian.Karagiannidis@uni-wh.de

${ }^{+}$Christian Karagiannidis and Michaela L. Merten contributed equally to this work.

${ }^{1}$ Department of Pneumology and Critical Care Medicine, Cologne-Merheim Hospital, Kliniken der Stadt Köln GmbH, Witten/Herdecke University Hospital, Ostmerheimer Strasse 200, D-51109 Cologne, Germany

Full list of author information is available at the end of the article
}

has been suggested to be clinically reasonable for direct visualization of tracheal puncture [5-10]. In particular, such guidance is anticipated to find the optimal puncture side, to avoid infringing of the tracheal cartilage and to secure placement of the cannula in the optimal position [11]. Thus, guidance of bronchoscopy during PDT has widely been accepted to reduce complication rates, most importantly the injury of the tracheal posterior wall [12-16]. Therefore, in Germany, 97.7\% of all ICUs use bronchoscopes to guide tracheostomy [17]. However, one of the major disadvantages of bronchoscopic guidance

(c) The Author(s). 2019 Open Access This article is distributed under the terms of the Creative Commons Attribution 4.0 International License (http://creativecommons.org/licenses/by/4.0/), which permits unrestricted use, distribution, and 
is the partial occlusion of the endotracheal tube (ET), leading to impaired alveolar ventilation. Surprisingly, few studies have evaluated the effect of bronchoscopy during PDT on gas exchange, in particular $\mathrm{CO}_{2}$ retention. Here, one early study has reported a mean increase in $\mathrm{PaCO}_{2}$ of $24 \mathrm{mmHg}[18,19]$. In addition, a substantial increase in $\mathrm{PaCO}_{2}$ has also been established during flexible bronchoscopy in stable patients using sedation practices [20].

However, $\mathrm{PCO}_{2}$ is frequently not monitored during PDT in clinically routine. Even though high levels of hypercapnia are suggested to be generally tolerated by patients, negative effects of hypercapnia on organ function, most importantly regulation of cerebral blood flow [20], worsening of right heart function $[21,22]$ and catecholamine excess in severe hypercapnia $[23,24]$ have also been reported. In particular, the impact of dynamic alterations with rapidly changing $\mathrm{PCO}_{2}$ and $\mathrm{pH}$ values on organ function in ICU patients with already existing organ dysfunction has yet not been fully elucidated. In this regard, there is no guideline-based recommendation regarding how to therapeutically respond to worsening alveolar ventilation resulting from the intervention. In particular, it also remains unclear whether actions such as choosing a larger ET size or increasing tidal volumes during the procedure are capable of attenuating or even avoiding the intervention-related increase in $\mathrm{PCO}_{2}$. This area has never been systematically investigated.

For these reasons, the present study was primarily aimed at assessing, firstly, the impact of bronchoscopy during PDT on periprocedural hypercapnic acidosis and, secondly, the impact of changing the ventilator settings in dependence of the tube size. Thereby, it was hypothesized that, first, there will be a significant increase in $\mathrm{PaCO}_{2}$ during PDT resulting in respiratory acidosis, and, secondly, that this increase could be attenuated by increasing the tidal volume $\left(\mathrm{V}_{\mathrm{t}}\right)$ during the procedure and by choosing larger ET sizes. Secondarily, it was also hypothesized that the increase in $\mathrm{PaCO}_{2}$ during PDT is a dynamic process, which could be further displayed by transcutaneous $\mathrm{PCO} 2$ monitoring $\left(\mathrm{PtcCO}_{2}\right)$. If so, this technique would be capable of helping physicians to more safely perform PDT.

\section{Methods}

The study was approved by the Ethics Committee of the Witten/Herdecke University (research ethics board number 101/2015 - August 2015) and registered at the German Clinical Trial Register and the WHO trial register (DRKS00011004).

\section{Study design}

Patients with acute respiratory failure requiring invasive mechanical ventilation following intubation and planned for PDT were included into the study. Patients were eligible if informed consent could be obtained from the caregivers or legal guardians, respectively, in advance and if ventilator settings revealed a positive end expiratory pressure (PEEP)-level of $\leq 15 \mathrm{cmH}_{2} \mathrm{O}$ and a $\mathrm{V}_{\mathrm{t}}$ of 6 $\mathrm{ml} / \mathrm{kg}$ predicted body weight (PBW), resulting in an arterial $\mathrm{pH}>7.20$. ET sizes had been determined clinically on individual requirements prior to the study, and these sizes were not subject to alteration during the study.

Prior to the intervention, all patients were ventilated with a fraction of inspired oxygen $\left(\mathrm{FiO}_{2}\right)$ of 1.0 and then sedated to a Richmond Agitation Sedation Scale (RASS) of -5 , with muscle relaxants then being administered (1 $\mathrm{mg} / \mathrm{kg}$ body weight rocuronium bromide). $\mathrm{PtcCO}_{2}$ was continuously monitored using a SenTec Digital Monitor with a sampling rate of one measurement per minute (SenTec Digital Monitoring System; SenTec AG; Ref.: 005856, MPB-Software: V05.00.15 and SMB-Software: V07.00.6; SenTec AG, Therwil, Switzerland) as described previously [21, 22]. Equilibrium measurements were established prior to intervention. A sensor was placed on the forehead of the patient at least $60 \mathrm{~min}$ prior to the start of the study.

Arterial blood gas analysis was performed at the beginning of the intervention (start), at the end (end) and at $30 \mathrm{~min}$ after the intervention (end $+30 \mathrm{~min}$ ). The beginning of the intervention was defined as the time when placing the bronchoscope into the endotracheal tube. Accordingly, the end of the intervention was defined as the time when the bronchoscope was removed after having successfully placed the tracheal cannula. A typical example is provided in Fig. 1.

Two groups of patients were consecutively investigated. For both groups, pressure-controlled ventilation (Servo-I, Maquet Cardiopulmonary, Rastatt, Germany)

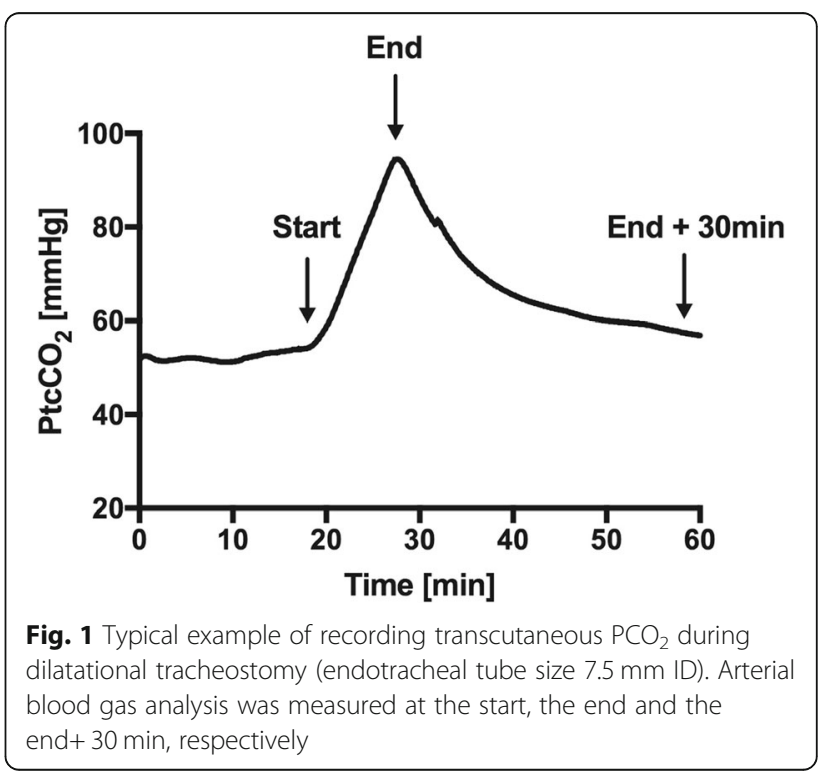


was used throughout the entire study. Initially, ventilation was aimed at achieving a $V_{t}$ of $6 \mathrm{ml} / \mathrm{kg} P B W$ as was done also clinically in these patients prior to the intervention (low $V_{t}$ group). Then, a $V_{t}$ of $12 \mathrm{ml} / \mathrm{kg}$ PBW was chosen in subsequent patients (high $V_{t}$ group). Investigators were not blinded for the $\mathrm{V}_{\mathrm{t}}$ groups. Adjustment to $12 \mathrm{ml} / \mathrm{kg}$ PBW for the purpose of the study was initiated just before the bronchoscope was inserted through the endotracheal tube. $V_{t}$ was then reduced to $6 \mathrm{ml} / \mathrm{kg}$ PBW immediately after the bronchoscope was removed from the endotracheal tube. No further changes in ventilator settings were dictated by the study protocol. Respiratory rate, PEEP and inspiration-to-expiration ratio were maintained at a level set by the clinician prior to the procedure.

Technically, PDT was guided by video bronchoscopy (Olympus BF-Q180, maximal diameter $5.5 \mathrm{~mm}$ ) and performed using the technique described by Ciaglia et al. (Ciaglia Blue Rhino ${ }^{\circ}$ G2, COOK medical, Bloomington, USA) [25]. Between the start and end of the procedure, the bronchoscope was not intermittently removed due to safety reasons (possible ET displacement) and also in order to keep the duration of the procedure at a minimum. Tracheostomy was positioned in the midline of the trachea below the second to fourth tracheal ring as described previously [26]. For that purpose, a tracheal cannula with an internal diameter (ID) of $8.0 \mathrm{~mm}$ was preferentially chosen. All interventions were performed by an experienced intensivist or by a trainee under the direct supervision of the experienced intensivist.

\section{Statistical analysis}

For statistical analysis, the Kruskal-Wallis one-way analysis of variance was used to compare three parameters, and the Mann-Whitney test was employed to compare 2 parameters. $\mathrm{PaCO}_{2}$ was compared to $\mathrm{PtcCO}_{2}$ at three different time points: start of the intervention, end of the intervention and $30 \mathrm{~min}$ after the end of the procedure. For this purpose, both correlation (spearman's correlation) and Bland-Altman analyses were performed using GraphPad prism version 7.

\section{Results}

Sixty-three patients were included in the study. Patient characteristics and baseline physiological data are provided in Table 1. In eight patients, tracheal rings were fractured without significant clinical impact, even after decannulation. The intervention was not interrupted or discontinued in any case.

\section{Low $\mathrm{V}_{\mathrm{t}}$ group}

Overall, 29 patients were investigated in the low $V_{t}$ group: 10 patients with an ET of $7.5 \mathrm{~mm}$ ID, 11 patients with an ET of $8.0 \mathrm{~mm} \mathrm{ID,} \mathrm{and} 8$ patients with an ET of
Table 1 Patient's characteristics, ventilator settings and blood gas analysis prior to tracheostomy (PBW - predicted body weight)

\begin{tabular}{lll}
\hline Main characteristics & $6 \mathrm{ml} / \mathrm{kg}$ PBW group & $12 \mathrm{ml} / \mathrm{kg}$ PBW group \\
\hline Patient Number & $\mathrm{N}=29$ & $\mathrm{~N}=34$ \\
Age [years] & $57.4 \pm 14.5$ & $59.5 \pm 12.8$ \\
Tracheostomy [day] & $16.8 \pm 8.3$ & $16.3 \pm 8.9$ \\
$\mathrm{SAPS} \|$ & $36.7 \pm 10.6$ & $36.5 \pm 10.0$ \\
$\mathrm{FiO}_{2}$ & $0.42 \pm 0.10$ & $0.41 \pm 11.5$ \\
$\mathrm{P} / \mathrm{F}$ ratio $[\mathrm{mmHg}]$ & $241.1 \pm 196.6$ & $211.6 \pm 66.7$ \\
$\mathrm{~V}_{\mathrm{t}}[\mathrm{ml}]$ & $461.8 \pm 102.3$ & $462.9 \pm 108.7$ \\
$\mathrm{Breathing}$ frequency $[/ \mathrm{min}]$ & $20.8 \pm 3.4$ & $20.2 \pm 3.0$ \\
Driving Pressure $\left[\mathrm{cmH}_{2} \mathrm{O}\right]$ & $14.6 \pm 4.8$ & $12.7 \pm 3.6$ \\
$\mathrm{PIP}\left[\mathrm{cmH}_{2} \mathrm{O}\right]$ & $26.1 \pm 5.8$ & $24.3 \pm 6.3$ \\
$\mathrm{PEEP}\left[\mathrm{cmH}_{2} \mathrm{O}\right]$ & $11.3 \pm 2.9$ & $11.6 \pm 3.1$ \\
$\mathrm{pH}_{\mathrm{PaO}}[\mathrm{mmHg}$ & $7.37 \pm 0.07$ & $7.36 \pm 0.06$ \\
$\mathrm{PaCO}_{2}[\mathrm{mmHg}$ & $81.8 \pm 14.7$ & $77.6 \pm 17.4$ \\
\hline
\end{tabular}

Data are presented as mean with standard deviation

$8.5 \mathrm{~mm}$ ID, respectively. The corresponding intervention time was $12 \pm 3,11 \pm 3$ and $9 \pm 3 \mathrm{~min}$, respectively. There was a statistically significant and substantial increase in $\mathrm{PaCO}_{2}$ during the intervention (start to end), whereas $\mathrm{PaCO}_{2}$ substantially decreased following the intervention (end $+30 \mathrm{~min}$ ) (Fig. 2). Correspondingly, pH significantly and substantially decreased and subsequently increased, respectively (Additional files 1 and 4).

\section{High VT group}

Overall, 34 patients were investigated in the high $\mathrm{V}_{\mathrm{t}}$ group: 11 patients with an ET of $7.5 \mathrm{~mm}$ ID, 13 patients with an ET of $8.0 \mathrm{~mm}$ ID and 10 patients with an ET of $8.5 \mathrm{~mm}$ ID, respectively. The corresponding intervention time was $10 \pm 3,10 \pm 3$ and $9 \pm 3 \mathrm{~min}$, respectively. There was a substantial increase in $\mathrm{PaCO}_{2}$ during the intervention (start to end), whereas $\mathrm{PaCO}_{2}$ substantially reduced following the intervention (end $+30 \mathrm{~min}$ ) (Fig. 2). Correspondingly, $\mathrm{pH}$ markedly decreased and subsequently increased, respectively (Additional files 1 and 4). However, changes in $\mathrm{PaCO}_{2}$ and $\mathrm{pH}$ were attenuated with larger tube sizes and even did not reach statistical significance when using an ET of $8.5 \mathrm{~mm}$ ID.

\section{Comparison of low and high $\mathrm{V}_{\mathrm{t}}$ groups}

The increase in $\mathrm{PaCO}_{2}$ and the reduction in $\mathrm{pH}$, respectively, were comparable with regard to different $V_{t}$ when using an ET of $7.5 \mathrm{~mm}$ ID (Figs. 3 and 4, Additional files 1, 2, 3 and 4). When using an ET of $7.5 \mathrm{~mm}$ ID, the minute ventilation decreased during the intervention to a minimum, and this ventilation was unchanged when comparing low and high $V_{t}$ (Fig. 5). In contrast, when using larger ET IDs, the minute ventilation during the 


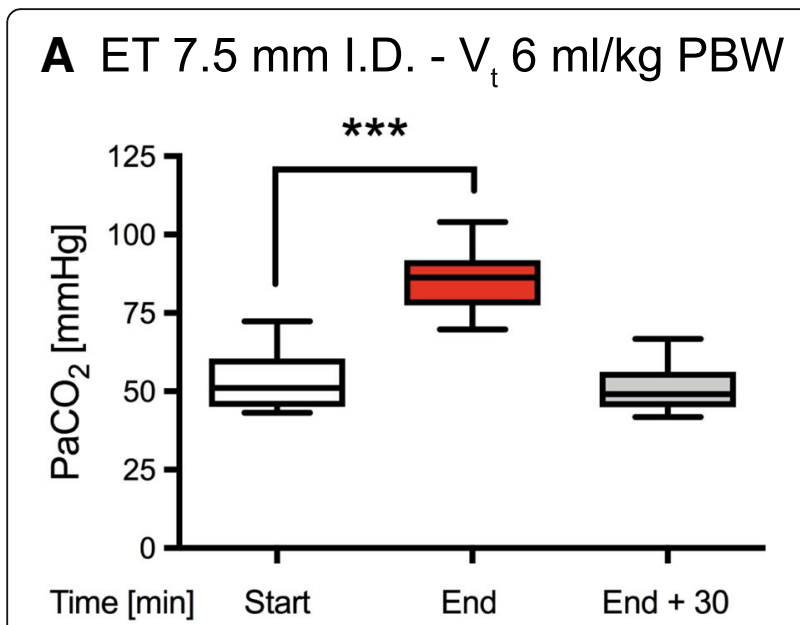

B ET $8.0 \mathrm{~mm}$ I.D. $-\mathrm{V}_{\mathrm{t}} 6 \mathrm{ml} / \mathrm{kg}$ PBW

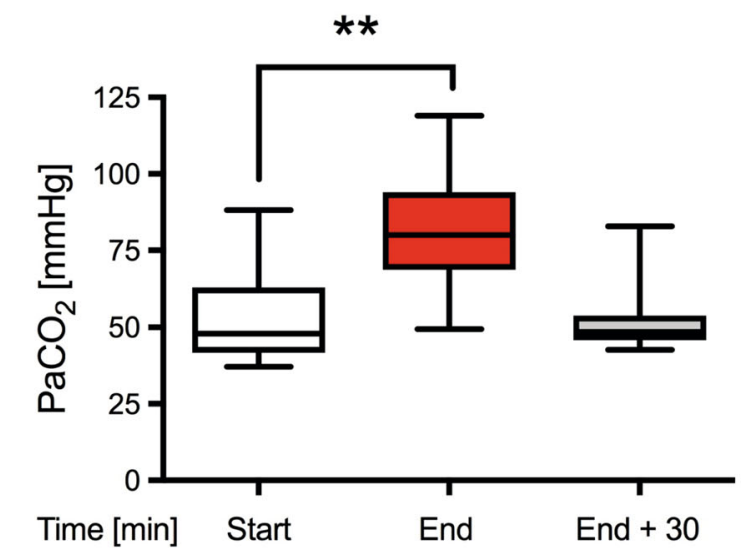

C ET $8.5 \mathrm{~mm}$ I.D. $-\mathrm{V}_{\mathrm{t}} 6 \mathrm{ml} / \mathrm{kg}$ PBW

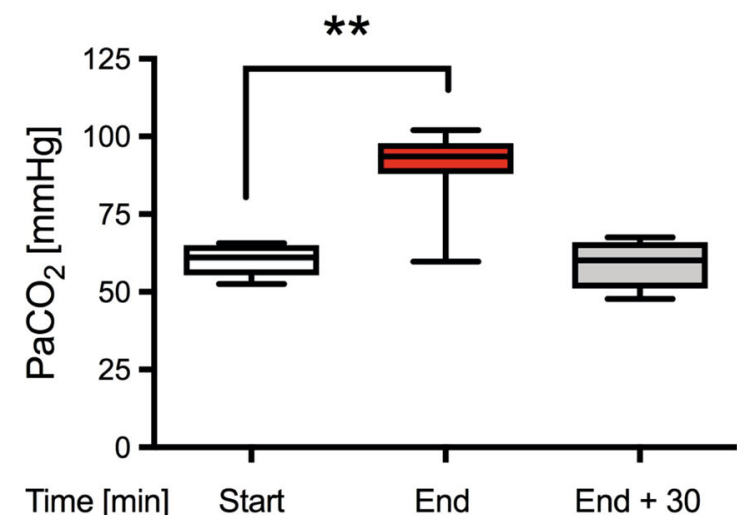

Fig. $2 \mathrm{PaCO}_{2}$ during dilatational tracheostomy. Tidal volume was set to $6 \mathrm{ml} / \mathrm{kg}$ PBW for the entire period. ${ }^{*} p \leq 0.05,{ }^{* *} p \leq 0.01$ and ${ }^{* * *} p \leq 0.001$. (ET - endotracheal tube, I.D. - internal diameter). Data were analyzed according to the diameter of the tube $(\mathbf{a}: 7.5 \mathrm{~mm}, \mathbf{b}$ : $8.0 \mathrm{~mm}$ and $\mathbf{c}: 8.5 \mathrm{~mm}$ ) intervention was higher when using high $V_{t}$ compared to low $\mathrm{V}_{\mathrm{t}}$. When comparing low and high $\mathrm{V}_{\mathrm{t}}$, the difference in the increase in $\mathrm{PaCO}_{2}$ and the decrease in $\mathrm{pH}$ during the intervention, respectively, were more evident with higher ET IDs. Thus, respiratory acidosis occurring during the intervention could be at best attenuated when using an ET ID of $8.5 \mathrm{~mm}$, while simultaneously using a $V_{t}$ of $12 \mathrm{ml} / \mathrm{kg}$ PBW.

\section{Comparison of $\mathrm{PaCO}_{2}$ and $\mathrm{PtcCO}_{2}$}

Hypercapnia immediately started to occur at the beginning of the intervention as assessed by $\mathrm{PtcCO}_{2}$ monitoring. A typical example of $\mathrm{PtcCO}_{2}$ monitoring during PDT is displayed in Fig. 1. $\mathrm{PaCO}_{2}$ and $\mathrm{PtcCO}_{2}$ were significantly correlated $(r=0.87, p<0.001$, Fig. 4a). The corresponding Bland-Altman analysis is displayed in Fig. 4b (Bias $0.65 \pm 9.4 \mathrm{mmHg}$ within the limits of agreement from -17.8 to $19.1 \mathrm{mmHg}$ ).

\section{Discussion}

The current study has demonstrated that there is a rapidly evolving respiratory acidosis during bronchoscopy-guided PDT. Thereby, the increase in $\mathrm{PaCO}_{2}$ is substantial and results from a reduced minute ventilation following bronchoscopy-related ET occlusion if pressure-controlled ventilation is used with established settings, aiming at lung protective ventilation. The present study has, furthermore, illustrated that an increase in $\mathrm{V}_{\mathrm{t}}$ from 6 to $12 \mathrm{ml} / \mathrm{kg} \mathrm{PBW}$ is capable of attenuating respiratory acidosis resulting from bronchoscopy-guided PDT. However, this effect was shown to be significantly dependent on ET size. Here, when using an ET of $7.5 \mathrm{~mm}$ ID, increasing $\mathrm{V}_{\mathrm{t}}$ as described above did not result in a significant attenuation of respiratory acidosis, and this lack of attenuation is suggested to be related to the observation that the ET is subtotally occluded by the bronchoscope when using an ET of $7.5 \mathrm{~mm}$ ID, thus preventing minute ventilation to be increased despite increasing inspiratory pressures aimed at achieving a $\mathrm{V}_{\mathrm{t}}$ of $12 \mathrm{ml} / \mathrm{kg}$ PBW. This work also provides evidence for the impact of smaller bronchoscopes potentially improving alveolar ventilation compared to larger ones, but this area was not investigated in the present study.

As an alternative approach to ET, using a laryngeal mask is suggested to be associated with an attenuation of the increase in $\mathrm{PCO}_{2}$. However, there is an ongoing debate on whether laryngeal masks should be used for PDT. In this regard, a recent Cochrane analysis [27] revealed a higher probability of a failing procedure and an uncertainty of serious adverse events when using laryngeal masks. Furthermore, at least in the ICU setting used for the current study changing the airway access is at risk for even severe complications, and this should be 


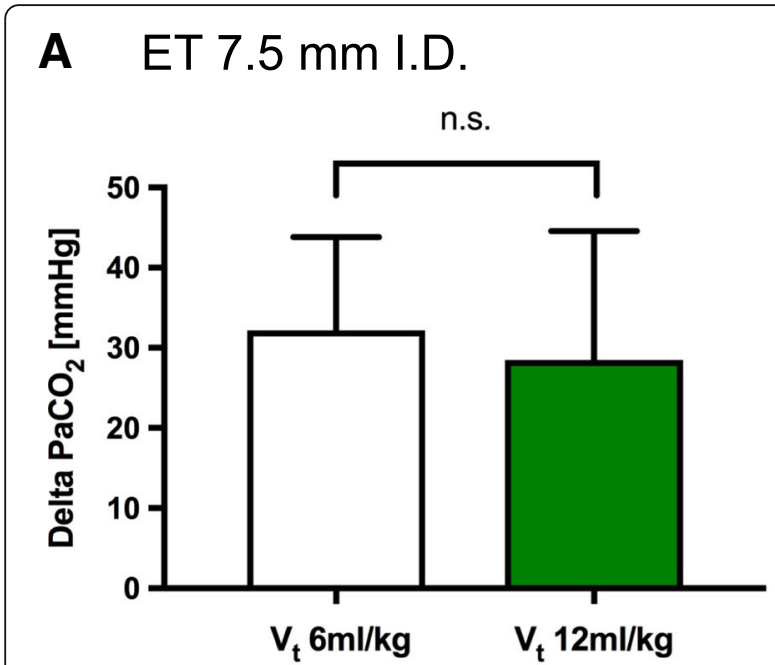

\section{B ET $8.0 \mathrm{~mm} \mathrm{I.D.}$}

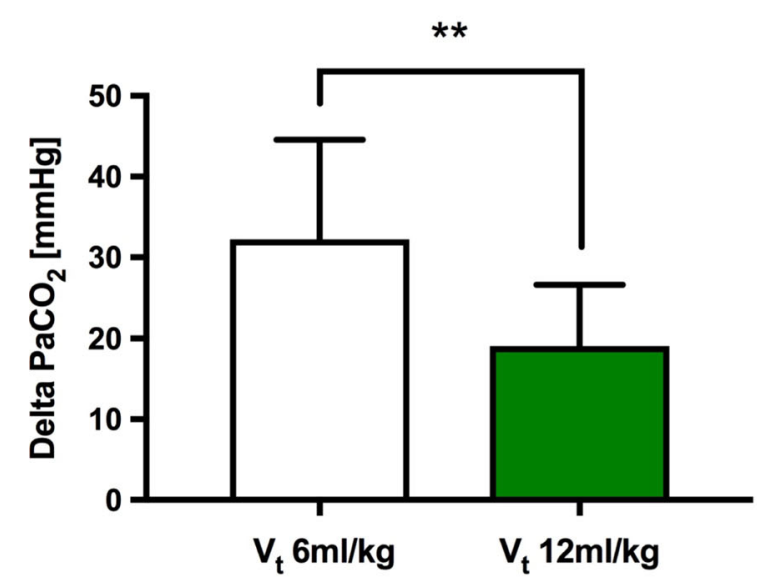

\section{ET $8.5 \mathrm{~mm}$ I.D.}

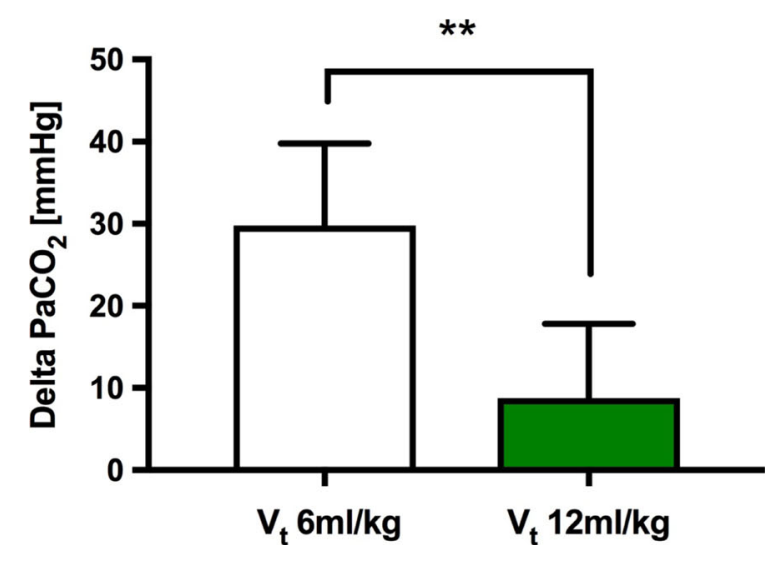

Fig. 3 Increase of $\mathrm{PaCO}_{2}$ during dilatational tracheostomy. Arterial blood gas analysis was performed at the beginning and end of the procedure. Patients were ventilated with tidal volumes $\left(V_{t}\right)$ of 6 or $12 \mathrm{ml} / \mathrm{kg}$ PBW during intervention. ${ }^{*} p \leq 0.05$ and ${ }^{* *} p \leq 0.01$. (ET endotracheal tube, I.D. - internal diameter). Data were analyzed according to the diameter of the tube $(\mathbf{a}: 7.5 \mathrm{~mm}, \mathbf{b}: 8.0 \mathrm{~mm}$ and c: $8.5 \mathrm{~mm})$

weighted against the benefit of a less severe increase in $\mathrm{PCO}_{2}$.

In contrast, when using larger ET IDs, minute ventilation was shown to be increased with higher $\mathrm{V}_{\mathrm{t}}$. Accordingly, respiratory acidosis occurring during bronchoscopy-guided PDT could be most successfully attenuated when combing an ET of $8.5 \mathrm{~mm}$ ID with a $\mathrm{V}_{\mathrm{t}}$ of $12 \mathrm{ml} / \mathrm{kg}$ PBW during the intervention. In the present study, however, only pressure-controlled ventilation was used. Theoretically, volume-controlled ventilation allowing for high inspiratory pressures is suggested to provide further advantages, at least if the airway is not sub-totally occluded when using considerably low ET sizes as discussed above. However, this is clearly dependent on how alarm settings are chosen, which in this study already reached $45 \mathrm{cmH}_{2} \mathrm{O}$. Therefore, best ventilator settings aimed at avoiding PDTrelated respiratory acidosis need to be established in the future. Finally, the study has also shown that $\mathrm{PtcCO}_{2}$ monitoring is a reliable tool for displaying the dynamic change of alveolar ventilation during bronchoscopyguided PDT in the ICU.

The present study has some important clinical implications. Firstly, vasodilatation as caused by hypercapnia and rapidly occurring respiratory acidosis can result in an increased cerebral pressure [20], electrolyte disturbances and impairment of infection control [28, 29], whereas pulmonary vasoconstriction is prone to worsening of right and left heart function [22, 23]. Even though impairments of infection control are suggested to be of minor importance given the short intervention time, all other physiological changes related to rapidly occurring respiratory acidosis may be of particular importance for patients with predisposing conditions such as neurosurgical patients or those with multi organ failure. Thus, respiratory acidosis occurring during bronchoscopy-guided PDT as described in the present study may be harmful for ICU patients.

Secondly, clinicians should be aware that the increase of $\mathrm{PCO}_{2}$ during for bronchoscopy-guided PDT could be attenuated by the combination of an increased $V_{t}(12$ versus $6 \mathrm{ml} / \mathrm{kg} P B W$ ) and a larger ET size ( $\geq 8 \mathrm{~mm} \mathrm{ID)}$ ), but this statement is not true when only using a smaller ET size $(<8 \mathrm{~mm}$ ID). Theoretically, changing the ET prior to the intervention could be advantageous when solely examining the results of the current findings, but this approach is suggested to be not generally 


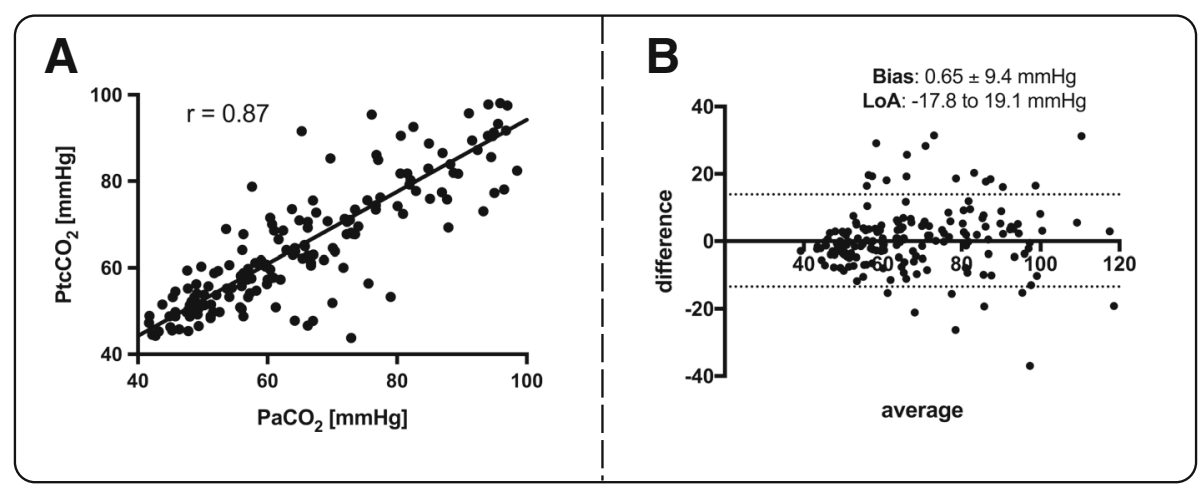

Fig. 4 Correlation of transcutaneous $\mathrm{PCO}_{2}\left(\mathrm{PtcCO}_{2}\right)$ and arterial $\mathrm{PCO}_{2}\left(\mathrm{PaCO}_{2}\right)(\mathbf{a})$. Corresponding Bland-Altman analysis are given in (b). $(r$ - spearman's correlation; LoA - Limits of Agreement). Please note that the bias line for the Bland-Altman analysis is not visible due to the observation that the bias was close to zero

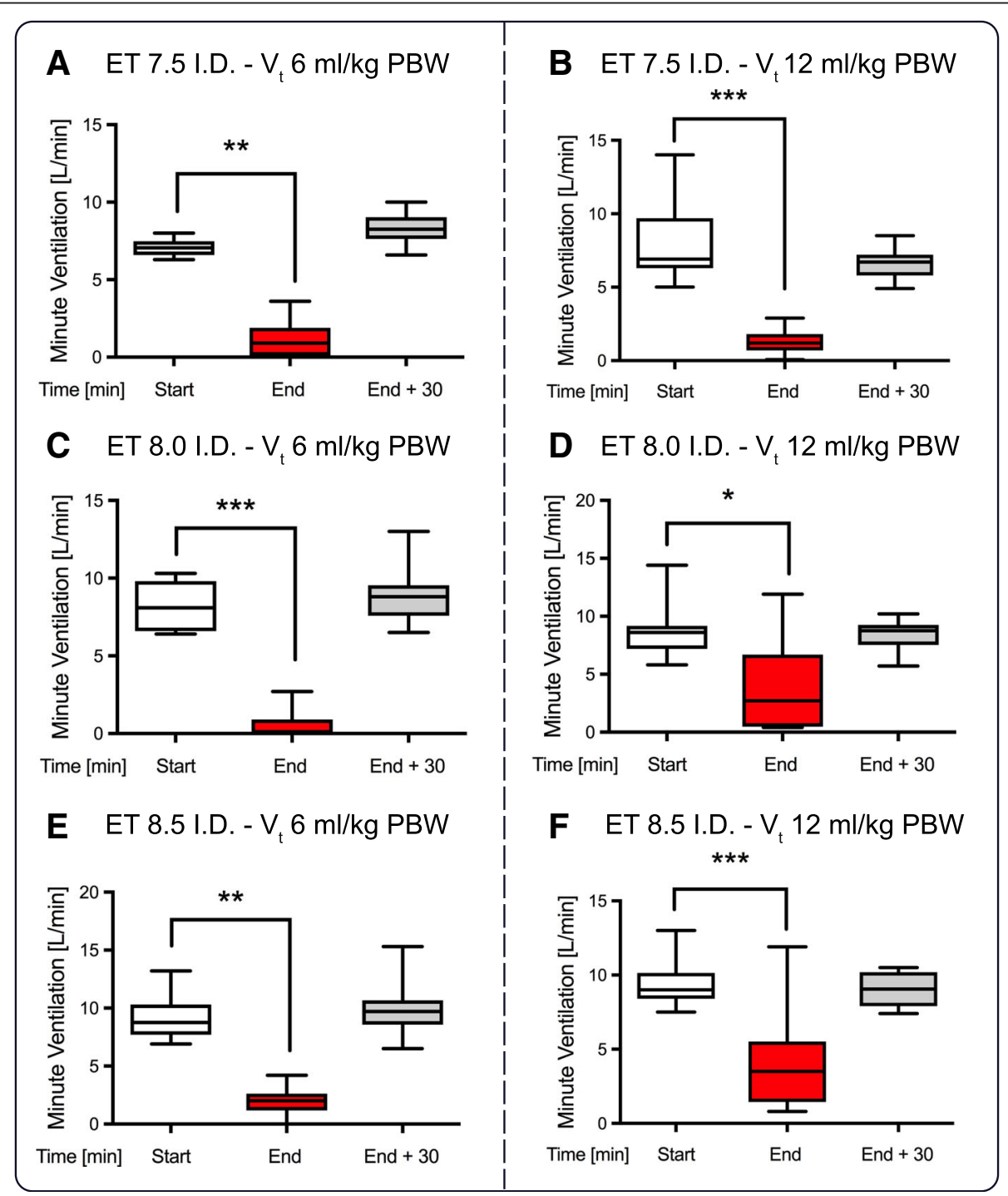

Fig. 5 Minute ventilation during dilatational tracheostomy. Tidal volume was set to $6 \mathrm{ml} / \mathrm{kg} \mathrm{PBW} \mathrm{(a,} \mathrm{c} \mathrm{and} \mathrm{e)} \mathrm{or} 12 \mathrm{ml} / \mathrm{kg}$ PBW (b, d and $\mathbf{f}$ ) for the entire period. ${ }^{*} p \leq 0.05,{ }^{* *} p \leq 0.01$ and ${ }^{* * *} p \leq 0.001$. (ET - endotracheal tube, I.D. - internal diameter) 
recommended for clinical routine due to the general risk of changing a tube for severely ill patients. Importantly, an increase in the $V_{t}$ was entirely restricted to the duration of the procedure; thus, lung protective ventilation is unlikely to be abandoned. In contrast, real alveolar ventilation is still reduced as evidenced by further increased $\mathrm{PCO}_{2}$ values. Therefore, restricting an increase in $V_{t}$ for the duration of the intervention is highly unlikely to cause harm for the lungs but is suggested to be capable of minimizing the occurrence of hypercapnia when using larger ET sizes as described above.

Thirdly, $\mathrm{PCO}_{2}$ immediately starts to increase at the beginning of the intervention and also steadily continues to increase until the intervention has finished. Accordingly, $\mathrm{pH}$ values consistently decrease, resulting in severe respiratory acidosis. Therefore, there is evidence to suggest that the intervention time plays a fundamental role in the occurrence of respiratory acidosis resulting from bronchoscopy-guided PDT. The duration of the intervention in the current study was in a clinically acceptable range. However, an extended duration of the intervention is prone to substantially aggravate respiratory acidosis, particularly if increasing the $V_{t}$ is unlikely to improve alveolar ventilation in case of using smaller ET sizes, as discussed above in detail. Therefore, the duration of the intervention must be kept at a minimum or the bronchoscope has to be removed intermittently to allow alveolar ventilation.

Finally, the current study also provides evidence that $\mathrm{PtcCO}_{2}$ monitoring is a reliable and helpful tool to assess the dynamic process of worsening hypercapnia. Importantly, the bias as calculated by Bland and Altman analysis ranged between -0.5 and $1.8 \mathrm{mmHg}$, a result which is suggested to be clinically acceptable, particularly in view of previous findings in ICU medicine [30, 31]. Thereby, $\mathrm{PtcCO}_{2}$ monitoring clearly provides 2 important clinical advantages. First, the trend of $\mathrm{PCO}_{2}$ evolution is individually accessible. Second, this technique overcomes the disadvantage of spot measurements with delayed result presentation as valid for arterial blood gas analysis. Clinically, the assessment of the dynamics in hypercapnia development may help the investigator to decide to intermittently remove the bronchoscope during the procedure to guarantee maintenance of alveolar ventilation. This area, however, was not addressed in the present study and requires further investigation also considering higher complication rates related to ET displacements and longer intervention duration.

In addition, $\mathrm{PtcCO}_{2}$ monitoring is also suggested to be superior over end tidal $\mathrm{PCO}_{2}$ monitoring because ventilation-perfusion mismatching regularly occurring in ICU patients is suggested to distort $\mathrm{PCO}_{2}$ measurements when using end tidal monitoring [32-34]. However, there was a significant range of the limits of agreement between arterial and transcutaneous $\mathrm{PCO}_{2}$ measurements in the present study, a range which was even somewhat higher than previously reported in patients receiving mechanical ventilation [32-34]. This observation may be attributed to the special clinical scenario with high individual stress levels when performing the intervention and catecholamine treatment. This drawback, however, could be overcome by relating individual arterial and transcutaneous $\mathrm{PCO}_{2}$ measurements prior to the intervention. Furthermore, the $\mathrm{PCO}_{2}$ trend over time is suggested to be at least as important as the exact $\mathrm{PCO}_{2}$ measurement during intervention.

There are, however, some limitations of the present study. Firstly, patients were not randomized to receive 6 or $12 \mathrm{ml} / \mathrm{kg}$ PBW. However, it is suggested that this lack of randomization did not affect the results given the clear differences between the 2 ventilatory approaches, the fact that patients were not aware of the modality chosen and the tight-fitting baseline characteristics of both groups. Secondly, the number of patients in each group defined by specific levels of $V_{t}$ and ET size was relatively small, and also not standardized, respectively. Here, the decision to select a specific ET size was taken in the emergency situation prior to the investigation, and changing ET tubes for standardisation was considered to be unethical.

\section{Conclusion}

In conclusion, the present study has demonstrated that hypercapnia and, consequently, profound respiratory acidosis following bronchoscopy-guided percutaneous dilatational tracheostomy evolves in a rapid and dynamic process. These changes were reportedly related to substantially reduced minute ventilation. Increasing the tidal volume from 6 to $12 \mathrm{ml} / \mathrm{kg}$ PBW was capable of attenuating the evolution of respiratory acidosis related to endotracheal tube occlusion occurring as a consequence of bronchoscopy. However, this effect was only evident when using larger endotracheal tube sizes of $\geq 8 \mathrm{~mm}$ ID.

\section{Additional files}

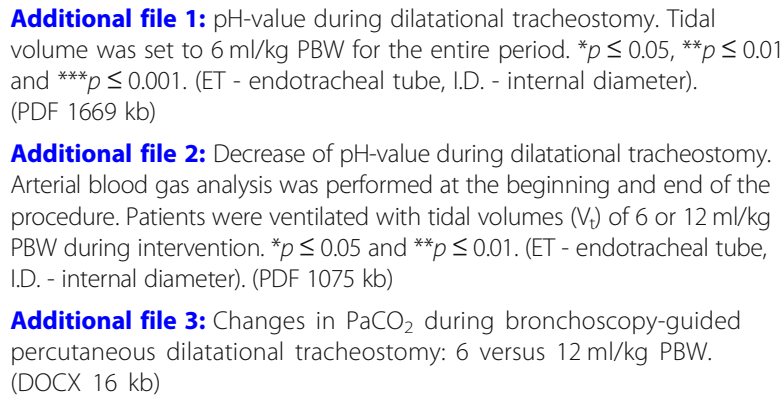

Additional file 1: $\mathrm{pH}$-value during dilatational tracheostomy. Tidal volume was set to $6 \mathrm{ml} / \mathrm{kg}$ PBW for the entire period. ${ }^{*} p \leq 0.05,{ }^{* *} p \leq 0.01$ and ${ }^{* *} p \leq 0.001$. (ET - endotracheal tube, I.D. - internal diameter). (PDF $1669 \mathrm{~kb}$ )

Additional file 2: Decrease of $\mathrm{pH}$-value during dilatational tracheostomy. Arterial blood gas analysis was performed at the beginning and end of the procedure. Patients were ventilated with tidal volumes $\left(V_{t}\right)$ of 6 or $12 \mathrm{ml} / \mathrm{kg}$ PBW during intervention. ${ }^{*} p \leq 0.05$ and ${ }^{* *} p \leq 0.01$. (ET - endotracheal tube, I.D. - internal diameter). (PDF $1075 \mathrm{~kb}$ )

Additional file 3: Changes in $\mathrm{PaCO}_{2}$ during bronchoscopy-guided percutaneous dilatational tracheostomy: 6 versus $12 \mathrm{ml} / \mathrm{kg}$ PBW. (DOCX $16 \mathrm{~kb}$ )

Additional file 4: Changes in $\mathrm{pH}$ during bronchoscopy-guided percutaneous dilatational tracheostomy: 6 versus 12 ml/kg PBW. (DOCX 16 kb) 


\section{Abbreviations}

ET: Endotracheal tube; $\mathrm{FiO}_{2}$ : Inspiratory fraction of oxygen; I.D: Internal diameter; ICU: Intensive care unit; $\mathrm{PaCO}_{2}$ : Arterial partial pressure of carbon dioxide; PBW: Predicted body weight; $\mathrm{PCO}_{2}$ : Partial pressure of carbon dioxide; PDT: Percutaneous dilatational tracheostomy; $\mathrm{PtcCO}_{2}$ : Transcutaneous partial pressure of carbon dioxide; RASS: Richmond Agitation Sedation Scale; $V_{t}:$ Tidal volume

\section{Acknowledgements}

Not applicable.

\section{Authors' contributions}

CK and MM had access to all data and took responsibility for the integrity of the data and the accuracy of the data analysis. CK and MM designed the study (together with SES). FM and SS participated in data acquisition and analysis. WW, LH and CK designed the concept of the manuscript; all the other authors contributed to the final drafting of the manuscript. All authors read and approved the final manuscript.

\section{Funding}

None.

\section{Availability of data and materials}

All data generated or analysed during this study are included in this published article.

\section{Ethics approval and consent to participate}

The present study was approved by the Institutional Review Board (Ethical committee of the University Witten/Herdecke No. 101/2015) and registered at the German Clinical Trial Register (DRKS) and the WHO trial register (DRKS00011004), registered 20th September 2016, with the first patient being enrolled on 30th September 2016. Prior to inclusion, written informed consent was obtained from the legal caregiver. The ethical committee approved the procedure for the collection of consent from legal caregivers https://www.drks.de/drks_web/navigate.do?navigationld=trial.HTML\&TRIAL_ ID=DRKS00011004.

\section{Consent for publication}

Not Applicable.

\section{Competing interests}

C.K. received travel grants and lecture fees from Maquet, Rastatt, Germany. Si.Sc. and M.M. have no conflicts of interest. St.St. received travel grants and lecture fees from Maquet Cardiopulmonary, Rastatt, Germany. F.M. received lecture fees from SenTec AG, Therwil, Switzerland. W.W. received fees for advisory board meetings and lectures from Maquet Cardiopulmonary, Rastatt, Germany. W.W. also received lecture fees from SenTec AG, Therwil, Switzerland. The hospital of the research group C.K. and W.W. received an open research grant from Maquet Cardiopulmonary, Rastatt, Germany unrelated to this work.

\section{Author details}

${ }^{1}$ Department of Pneumology and Critical Care Medicine, Cologne-Merheim Hospital, Kliniken der Stadt Köln GmbH, Witten/Herdecke University Hospital, Ostmerheimer Strasse 200, D-51109 Cologne, Germany. ${ }^{2}$ Dept of Intensive Care Medicine, Amsterdam UMC, location VUmc, Amsterdam, The Netherlands.

Received: 7 May 2019 Accepted: 6 August 2019

Published online: 09 August 2019

\section{References}

1. Dempsey GA, Morton B, Hammell C, Williams LT, Tudur Smith C, Jones T. Long-term outcome following tracheostomy in critical care: a systematic review. Crit Care Med. 2016:44(3):617-28.

2. Vargas M, Sutherasan Y, Antonelli M, Brunetti I, Corcione A, Laffey JG, Putensen C, Servillo G, Pelosi P. Tracheostomy procedures in the intensive care unit: an international survey. Crit Care. 2015;19:291.

3. Freeman BD, Kennedy C, Coopersmith CM, Buchman TG. Examination of non-clinical factors affecting tracheostomy practice in an academic surgical intensive care unit. Crit Care Med. 2009;37(12):3070-8.
4. Freeman BD, Borecki IB, Coopersmith CM, Buchman TG. Relationship between tracheostomy timing and duration of mechanical ventilation in critically ill patients. Crit Care Med. 2005;33(11):2513-20.

5. Hinerman R, Alvarez F, Keller CA. Outcome of bedside percutaneous tracheostomy with bronchoscopic guidance. Intensive Care Med. 2000; 26(12):1850-6.

6. Fernandez L, Norwood S, Roettger R, Gass D, Wilkins H 3rd. Bedside percutaneous tracheostomy with bronchoscopic guidance in critically ill patients. Arch Surg. 1996;131(2):129-32.

7. Madsen KR, Guldager H, Rewers M, Weber SO, Kobke-Jacobsen K, White J, Danish Society of A, Intensive C, Danish Society of Intensive Care M. Danish Guidelines 2015 for percutaneous dilatational tracheostomy in the intensive care unit. Dan Med J. 2015;62(3):C5042.

8. Gobatto AL, Besen BA, Tierno PF, Mendes PV, Cadamuro F, Joelsons D, Melro L, Carmona MJ, Santori G, Pelosi P, et al. Ultrasound-guided percutaneous dilational tracheostomy versus bronchoscopy-guided percutaneous dilational tracheostomy in critically ill patients (TRACHUS): a randomized noninferiority controlled trial. Intensive Care Med. 2016;42(3): 342-51.

9. Durbin CG Jr. Techniques for performing tracheostomy. Respir Care. 2005; 50(4):488-96.

10. Barba CA, Angood PB, Kauder DR, Latenser B, Martin K, McGonigal MD, Phillips GR, Rotondo MF, Schwab CW. Bronchoscopic quidance makes percutaneous tracheostomy a safe, cost-effective, and easy-to-teach procedure. Surgery. 1995;118(5):879-83.

11. Fikkers BG, Staatsen M, van den Hoogen FJ, van der Hoeven JG. Early and late outcome after single step dilatational tracheostomy versus the guide wire dilating forceps technique: a prospective randomized clinical trial. Intensive Care Med. 2011;37(7):1103-9.

12. Smith D, Loschner A, Rubio E. Routine use of bronchoscopy in percutaneous tracheostomy. J Crit Care. 2017;41:331.

13. Walz MK, Peitgen K, Thurauf N, Trost HA, Wolfhard U, Sander A, Ahmadi C, Eigler FW. Percutaneous dilatational tracheostomy--early results and long-term outcome of 326 critically ill patients. Intensive Care Med. 1998;24(7):685-90.

14. De Leyn P, Bedert L, Delcroix M, Depuydt P, Lauwers G, Sokolov Y, Van Meerhaeghe A, Van Schil P, Belgian Association of P, Belgian Association of Cardiothoracic S. Tracheotomy: clinical review and guidelines. Eur J Cardiothorac Surg. 2007;32(3):412-21.

15. Karagiannidis C, Velehorschi V, Obertrifter B, Macha HN, Linder A, Freitag L. High-level expression of matrix-associated transforming growth factor-beta1 in benign airway stenosis. Chest. 2006;129(5):1298-304.

16. Combes A, Luyt CE, Nieszkowska A, Trouillet JL, Gibert C, Chastre J. Is tracheostomy associated with better outcomes for patients requiring longterm mechanical ventilation? Crit Care Med. 2007;35(3):802-7.

17. Kluge S, Baumann HJ, Maier C, Klose H, Meyer A, Nierhaus A, Kreymann G. Tracheostomy in the intensive care unit: a nationwide survey. Anesth Analg. 2008;107(5):1639-43.

18. Reilly PM, Sing RF, Giberson FA, Anderson HL 3rd, Rotondo MF, Tinkoff GH, Schwab CW. Hypercarbia during tracheostomy: a comparison of percutaneous endoscopic, percutaneous Doppler, and standard surgical tracheostomy. Intensive Care Med. 1997;23(8):859-64.

19. Gemma M, Cozzi S, Cipriani A. Hypercarbia during tracheostomy. Intensive Care Med. 1998;24(3):279-80.

20. Meng L, Gelb AW. Regulation of cerebral autoregulation by carbon dioxide. Anesthesiology. 2015;122(1):196-205.

21. Karagiannidis C, Strassmann S, Philipp A, Muller T, Windisch W. Veno-venous extracorporeal $\mathrm{CO} 2$ removal improves pulmonary hypertension in acute exacerbation of severe COPD. Intensive Care Med. 2015;41(8):1509-10.

22. Mekontso Dessap A, Charron C, Devaquet J, Aboab J, Jardin F, Brochard L, Vieillard-Baron A. Impact of acute hypercapnia and augmented positive end-expiratory pressure on right ventricle function in severe acute respiratory distress syndrome. Intensive Care Med. 2009;35(11):1850-8.

23. Millar RA. Plasma adrenaline and noradrenaline during diffusion respiration. J Physiol. 1960;150:79-90.

24. Thorens JB, Jolliet P, Ritz M, Chevrolet JC. Effects of rapid permissive hypercapnia on hemodynamics, gas exchange, and oxygen transport and consumption during mechanical ventilation for the acute respiratory distress syndrome. Intensive Care Med. 1996;22(3):182-91.

25. Ciaglia P, Firsching R, Syniec $C$. Elective percutaneous dilatational tracheostomy. A new simple bedside procedure; preliminary report. Chest. 1985;87(6):715-9. 
26. Winkler WB, Karnik R, Seelmann O, Havlicek J, Slany J. Bedside percutaneous dilational tracheostomy with endoscopic guidance: experience with 71 ICU patients. Intensive Care Med. 1994;20(7):476-9.

27. Strametz R, Bergold MN, Weberschock T. Laryngeal mask airway versus endotracheal tube for percutaneous dilatational tracheostomy in critically ill adults. Cochrane Database Syst Rev. 2018;11:CD009901.

28. Curley G, Laffey JG, Kavanagh BP. Bench-to-bedside review: carbon dioxide. Crit Care. 2010;14(2):220.

29. Vadasz I, Hubmayr RD, Nin N, Sporn PH, Sznajder JI. Hypercapnia: a nonpermissive environment for the lung. Am J Respir Cell Mol Biol. 2012; 46(4):417-21.

30. Rodriguez P, Lellouche F, Aboab J, Buisson CB, Brochard L. Transcutaneous arterial carbon dioxide pressure monitoring in critically ill adult patients. Intensive Care Med. 2006;32(2):309-12.

31. Spelten O, Fiedler F, Schier R, Wetsch WA, Hinkelbein J. Transcutaneous PTCCO2 measurement in combination with arterial blood gas analysis provides superior accuracy and reliability in ICU patients. J Clin Monit Comput. 2017;31(1):153-8.

32. Schwarz SB, Windisch W, Magnet FS, Schmoor C, Karagiannidis C, Callegari J, Huttmann SE, Storre JH. Continuous non-invasive PCO2 monitoring in weaning patients: transcutaneous is advantageous over end-tidal PCO2. Respirology. 2017;22(8):1579-84.

33. Storre JH, Magnet FS, Dreher M, Windisch W. Transcutaneous monitoring as a replacement for arterial PCO (2) monitoring during nocturnal non-invasive ventilation. Respir Med. 2011;105(1):143-50.

34. Huttmann SE, Windisch W, Storre JH. Techniques for the measurement and monitoring of carbon dioxide in the blood. Ann Am Thorac Soc. 2014;11(4): $645-52$.

\section{Publisher's Note}

Springer Nature remains neutral with regard to jurisdictional claims in published maps and institutional affiliations.

Ready to submit your research? Choose BMC and benefit from:

- fast, convenient online submission

- thorough peer review by experienced researchers in your field

- rapid publication on acceptance

- support for research data, including large and complex data types

- gold Open Access which fosters wider collaboration and increased citations

- maximum visibility for your research: over $100 \mathrm{M}$ website views per year

At $\mathrm{BMC}$, research is always in progress.

Learn more biomedcentral.com/submissions 